\title{
Clinical Profile and outcome of envenomous snake-bite at tertiary care centre in western Maharashtra
}

\author{
Virendra C. Patil', Harsha V. Patil' ${ }^{2}$, Avinash Patil', Vaibhav Agrawal' \\ ${ }^{1}$ Department of Medicine,Krishna Institute of Medical Sciences University, Dhebewadi Road, Karad, \\ Satara District, Maharashtra - 415 110, India \\ ${ }^{2}$ Department of Microbiology, Krishna Institute of Medical Sciences University, Dhebewadi Road, Karad, \\ Satara District, Maharashtra - 415 110, India
}

\section{ABSTRACT}

Background: Venomous snake bite is a common and frequently devastating environmental and occupational disease, especially in rural areas of Maharashtra India. Aims \& Objectives: To determine the clinical profile and outcome of snakebite cases in rural western Maharashtra. Material \& Methods: This was a retrospective study conducted over one year period (January 2009 to December 2009) at a tertiary health care centre in Maharashtra. Results: Out of 167 admitted snakebite $103(61.67 \%)$ were complicated snake bites. Total $88(85.43 \%)$ patients were with vasculo-toxic snake bite. Total 15 $(14.56 \%)$ patients were with neuroparalytic snakebite. Total 35 (39.77\%) patients out of 88 with vasculotoxic snakebite developed local cellulitis requiring fasciotomy and or debridement, 17 (19.31\%) patients had clinical and laboratory parameters favoring DIC. Total $12(13.63 \%)$ patients had ARF, one developed AMI and one developed cortical venous sinus thrombosis (CVT). Out of 88 patients with vasculotoxic snakebite 2 died with case fatality rate of $2.27 \%(2 / 88)$. Out of 15 patients with neuroparalytic snake bite $13(86.66 \%)$ required artificial ventilatory support and one patient developed delayed peripheral neuropathy. Overall mortality was 1.94\% (2/103). The needle to ASV time was positively correlated with duration of hospital admission, complications and mortality (' $\left.\mathrm{p}^{\prime}<0.02\right)$. Conclusions: Snakebite is a common life-threatening emergency in the study area. Delay in hospitalization is associated with poor prognosis and increased mortality rate due to consumptive coagulopathy, renal failure and respiratory failure. Unusual complications like AMI, CVT and delayed peripheral neuropathy were observed in present study.

Key words: Complicated snake bites, ARF, AMI, DIC, ASV

\section{INTRODUCTION}

Snakebite is a common acute medical emergency faced by rural populations in tropical and subtropical countries. There are no accurate records available to determine the exact epidemiological or even mortality in snakebite cases in Maharashtra. In India more than 20,00,000 snake bites are reported annually, of which 35,000 to 50,000 people die ${ }^{1}$. Its public health importance has been largely ignored by medical science. Snake-bites are the common

\footnotetext{
Address for correspondence: Dr. Virendra C. Patil

Krishna Institute of Medical Sciences University

Dhebewadi Road, Karad, Satara District

Maharashtra-415 110, India

E-mail: virendracpkimsu@rediffmail.com
}

DOI: $10.5530 /$ ijmedph.4.2011.7 cause of morbidity and mortality in tropical countries. In India, there are 216 species of snakes, of which only four are venomous snakes (cobra, krait, Russell's viper and saw scaled viper). Snake venoms are rich in protein and peptide toxins that have specificity for a wide range of tissue receptors, making them clinically challenging and scientifically fascinating, especially for drug design ${ }^{2}$. Although the full burden of human suffering attributable to snake bite remains obscure, hundreds of thousands of people are known to be envenomed and tens of thousands are killed or maimed by snakes every year. South Asia is the world's most heavily affected region, due to its high population density, widespread agricultural activities, numerous venomous snake species and lack of functional snake bite control programs. Poorly informed rural populations often apply inappropriate first-aid measures and vital time is lost before the victim is transported to a treatment centre, where cost of treatment can constitute an additional hurdle ${ }^{3,4}$. The deficiency of snake bite 
management in South Asia is multi-causal and requires joint collaborative efforts from researchers, anti-venom manufacturers, policy makers, public health authorities and international funders ${ }^{5}$. Snake-bite is one of the most life-threatening bio-weapon system in the nature which may cause local to systemic complication the form of neurotoxicity or haematotoxicity. This study was conducted at tertiary care centre in western Maharashtra, which is one of the fast growing agricultural areas, to determine the clinical profile, complications and outcome of envenomous snake-bite cases.

\section{MATERIAL \& METHODS}

This was a retrospective, descriptive and observational study conducted between January 2009 to December 2009 at the Krishna Institute of medical sciences Karad, a tertiary health care centre in western Maharashtra, India. Out of 167 admitted snakebite 103 were complicated snake bite and 64 were uncomplicated snakebites. One hundred and three cases with history of snakebite of both genders were analysed. Clinical confirmation of snakebite with envenoming was by identification of the dead snake brought by victims and by clinical signs and symptoms such as absent or minimum local signs, pain in abdomen proceeding to neuroparalysis in the victim slept on floor bed, suggestive of krait bite. Rapid development swelling at the site of fangs marks with ecchymosis with rapid development of neuro-paralysis, respiratory depression suggestive of cobra bite. Severe local edema with fangs marks, active bleeding from fangs marks with rapid development of systemic bleeding with positive 20 minute whole blood clotting test (20WBCT) suggestive of Russell viper bite ${ }^{6}$. Slow development mild local edema with fangs marks, delayed development of local ecchymosis and systemic bleeding (20WBCT) in a case of Eh bite. Clotting time (CT) was the main bedside procedure, to assess the degree of envenomation in vasculotoxic snakebite. The diagnosis of snake-bite was established on the basis of a history of snake-bite with examination of the killed snake in 45 cases and, in the remaining, by correlating the clinical manifestations and recognition of the snakes by patients and bystanders. Bites due to cobras and kraits were classified as neurotoxic bites and those due to saw-scaled viper (Echis carinatus) and Russell viper as vasculotoxic bites. Clinical data including age, sex and occupation of the victims, the site of bite, time of bite, time between bite and presentation, clinical manifestations, complications and outcome were obtained from the case records and entered in a computer database for analysis.
The patients were divided into 4 groups based on their clinical manifestations.

1. No symptoms or signs of envenomation (uncomplicated snakebite)

2. Presence of local symptoms and signs only (complicated snakebite)

3. Presence of local symptoms and signs along with systemic manifestations of envenomation. (complicated snakebite with acute renal failure)

4. Neuroparalytic snakebite

All patients were given tetanus toxoid and antiinflammatory drugs in the form of chymotypsin. Local swelling was treated with glycerine and magnesium sulphate soakage with limb elevation. Adequate hydration was maintained and antibiotics were used where they are indicated. Debridement and fasciotomy was done if signs of cellulitis and compartment syndrome developed. All neuroparalytic snake bites were treated with neostigmine and atropine cycles depending on the clinicalimprovement of ptosis, head lag and respiratory paralysis. Strict input and output chart was monitored. Certain investigations were repeated as and when required like renal function tests, electrolytes, urine for hematuria, bleeding and clotting time, arterial blood gas analysis (ABGA) chest radiograph and ECG. All complicated snake bites were treated with polyvalent ASV. The anti-snake venom (ASV) was administered by the intravenous route after written and informed consent. Skin test was done before starting ASV (1 $\mathrm{ml}$ of 1:100 diluted) was given subcutaneously. ASV was diluted in $200 \mathrm{ml}$ of normal saline and depending on type of bite local and systemic signs of envenomation 50 unit, 100 units, 150 units, 200 units, up to 300 units of ASV was used. Anti-venom dosing recommendations are based on the quantity of particular venom [in milligrams $(\mathrm{mg})$, dry weight] that can be neutralized by each milliliter ( $\mathrm{ml}$ ) of anti-venom. In India, each milliliter of polyvalent anti-venom is supposed to neutralize: $0.6 \mathrm{mg}$ of Indian cobra venom; $0.6 \mathrm{mg}$ of Russell's viper (Daboia russelii) venom; $0.45 \mathrm{mg}$ of Common krait (Bungarus caeruleus) venom; and $0.45 \mathrm{mg}$ of Saw scaled viper (Echis carinatus) venom ${ }^{7}$.

ASV was recommended if one of the following features were observed in patients with history of snake-bite

1. Local swelling more than half of the bitten limb in absence of tourniquet, rapidly increasing edema and development of compartmental syndrome 
Patil, et al.: Clinical Profile and outcome of envenomous snake-bite at tertiary care centre

2. Development of tender enlarged lymph-nodes

3. Blister formation over involved limb

4. Spontaneous bleeding from bite site, venouspuncture site, haematuria

5. Positive 20 minute whole blood clotting test

6. Vomiting contraction of frontalis, ptosis, blurring of vision, parasthesia around mouth

7. Hypotension, shock, arrhythmias

8. Dark colour urine, oliguria, anuria,

\section{RESULTS}

\section{Clinical profile of snake bite envenomation}

Out of total 103 snake-bites 68 were males among vasculotoxic snake-bite and 9 were in neuroparalytic snakebite $(74.75 \%)$. Total 20 females were with vasculotoxic snake-bite and 6 were with neuroparalytic snake-bite (25.24\%). Total $87(84.46 \%)$ snakes were identified by history of snake-bite with examination of the killed snake, by correlating the clinical manifestations and recognition of the snakes by patients and bystanders. Out of 88 vasculotoxic snake-bite 70 were Russell viper and 8 were Saw scaled viper. Out of 15 neuroparalytic snake bite 9 were identified (cobra: 7 and krait: 2). Total 81 (78.64\%) patients admitted with in 6 hours of snake-bite and 22 $(21.35 \%)$ patients admitted after 6 hours of snake-bite. Lower limb bite was present in $83(80.58 \%)$ and upper limb bite was present in $20(19.41 \%)$. Local edema was present in $88(100 \%)$. Cellulitis was found in 35 (39.77\%) patients. Oligurea/ anuria were the presenting feature in $12(14.56 \%)$ patients with vasculotoxic snake-bite. Gum bleeding was found in $7(7.95 \%)$ patients with vasculotoxic snake-bite with DIC. Total 9 (10.22\%) patients had hematuria and $5(5.68 \%)$ patients had hematemesis. Total one $(1.13 \%)$ patient had cardiac chest pain, 7 (6.66\%) had abdominal pain and $9(8.73 \%)$ patients had vomiting. One $(1.13 \%)$ patients had altered sensorium with seizure. Total $19(18.44 \%)$ patients had breathlessness. Total $13(86.66 \%)$ had ptosis, $13(86.66 \%)$ had head lag and 7 patients had diplopia as presenting feature amongst neuroparalytic snake-bite. (Table 1 \& Figure 1) The mean ages for males were 32 year $( \pm 13)$ and for females were 29 years $( \pm 9)$. The mean hemoglobin was $11.5 \mathrm{gm} \%$ ( \pm 3.6$)$. The mean for BUL was $82 \mathrm{mg}( \pm 27)$ and for Sr. creatinine $6.5( \pm 2.6)$ amongst 88 vasculotoxic snake-bite. The mean for bleeding time was 3 minute $( \pm 30 \mathrm{sec})$, for clotting time $26 \mathrm{~min}( \pm 11)$ and for Platelet count 73,000 $\mathrm{cmm}( \pm 27,000)$. The mean for dose of ASV required for vasculotoxic snakebites were 250 units $( \pm 100)$ and for neuroparalytic snakebite 150 units $( \pm 50)$. The mean

\begin{tabular}{lcc}
\multicolumn{3}{l}{ Table 1: Clinical profile of snake bite envenomation } \\
\hline Variables & Total & Percent \\
\hline Males & $77(68: 9)$ [vasculotoxic: & 74.75 \\
& neuroparalytic] & \\
Female & 26 (20:6) [vasculotoxic: & 25.24 \\
& neuroparalytic] & \\
Admission <6 hours of bite & 81 & 78.64 \\
Admission >6 hours of bite & 22 & 21.35 \\
Snake identified & 87 & 84.46 \\
Lower limb bite & 83 & 80.58 \\
Upper limb bite & 20 & 19.41 \\
Local edema & 88 & 100 \\
Cellulitis & 35 & 39.77 \\
Oligurea/ anuria & 12 & 14.56 \\
Gum bleeding & 7 & 7.95 \\
Hematuria & 9 & 10.22 \\
Hematemesis & 5 & 5.68 \\
Chest pain & 1 & 1.13 \\
Abdominal pain & 7 & 46.66 \\
Vomiting & 9 & 8.73 \\
Altered sensorium & 1 & 1.13 \\
Breathlessness & 19 & 18.44 \\
Ptosis & 13 & 86.66 \\
Head lag & 13 & 88.66 \\
Diplopia & 7 & 46.66 \\
\hline
\end{tabular}

duration of admission for vasculotoxic snake bite was 10 hours $( \pm 4)$ and for neuroparalytic snake bite was 6 hours $( \pm 2)$. (Table 2)

\section{Complications of snakebite with envenomation}

Total $88(85.43 \%)$ patients were had complicated vasculotoxic snake bite. Out of total 88 patients with complicated vasculotoxic snake-bite 35 (39.77\%) local and spreading cellulitis which required surgical interventions in the form of debridement or fasciotomy. Total $12(13.68 \%)$ patients developed acute renal failure amongst 88 patients with vasculotoxic snake-bite. Out of $12(13.63 \%)$ patients with acute renal failure $9(75 \%)$ had anuric and $3(25 \%)$ had oliguric renal failure. All 9 patients with anuric renal failure required hemodialysis (daily). Out of 9 patients with anuric renal failure 5 had acute pulmonary edema which was treated with hemodialysis. (Figure 2) Three patients with oliguric renal failure treated with maintenance of hydration and treatment of DIC. Total $2(2.27 \%)$ patients had hyperkalemia those who presented with anuric acute renal failure which was treated with hemodialysis (Figure 3). Total 17 (19.31\%) patients had clinical and laboratory parameters favoring DIC. Patients with DIC were treated with maintenance of hydration, platelets, whole blood and FFP transfusion. Out of 88 patients with vasculotoxic snake-bite one $(1.13 \%)$ had anterior wall AMI. One (1.13\%) 49 year old male patient had cortical venous sinus thrombosis (CVT). Total $15(14.56 \%)$ patients had neuroparalytic snake bite. 


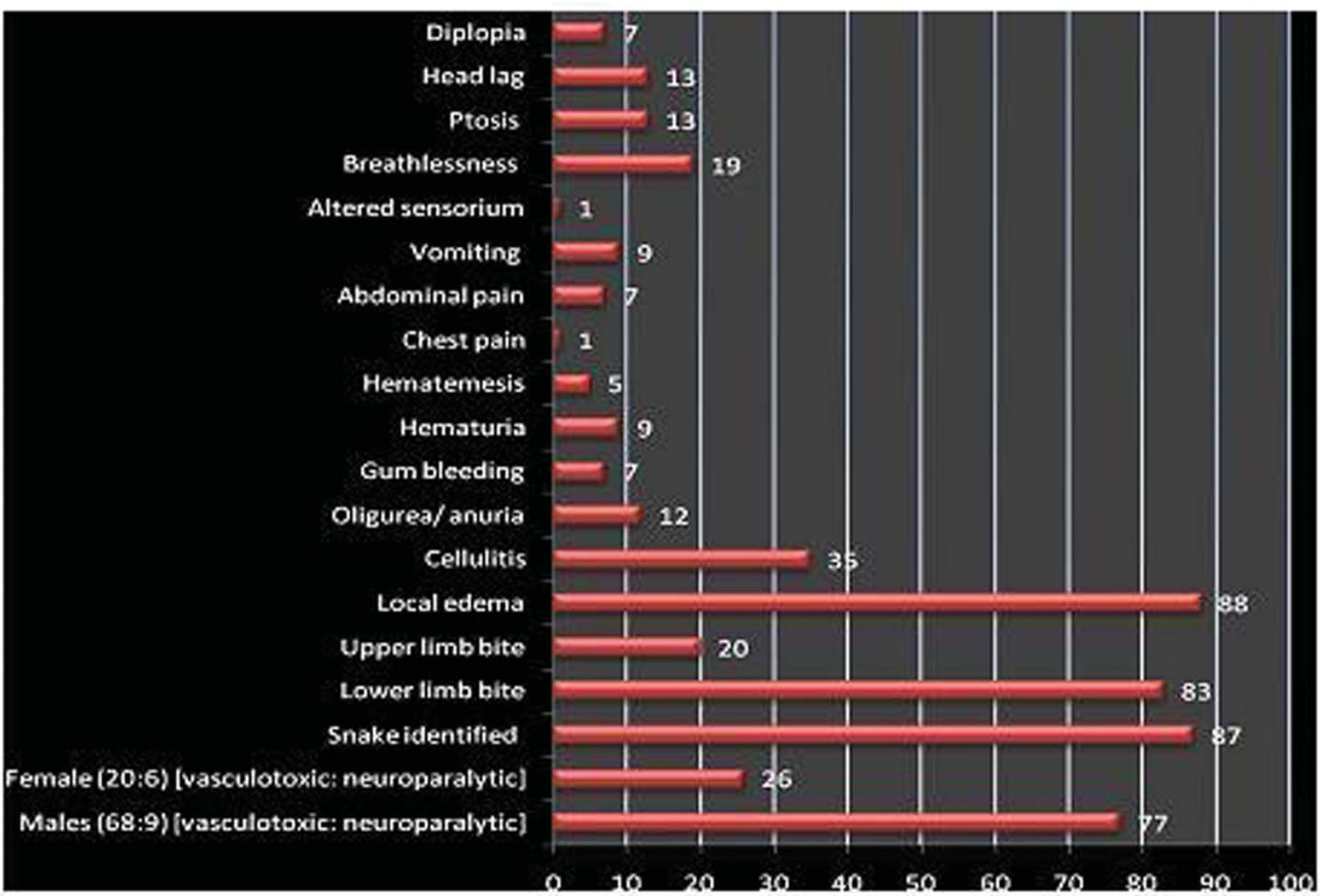

Figure 1: Clinical profile of envenomous snake-bite

\begin{tabular}{lcc}
\multicolumn{3}{l}{ Table 2: Laboratory profile of envenomous snake bite } \\
\hline Variables & Mean & Standard deviation \\
\hline Males & $32 \pm 13$ & \pm 13 \\
Females & 29 & \pm 9 \\
Hb (gm\%) & 11.5 & \pm 3.6 \\
BUL (mg) & 82 & \pm 27 \\
Sr. Creatinine (mg) & 6.5 & \pm 2.6 \\
BT (min) & 2 & $\pm 30 \mathrm{sec}$ \\
CT (min) & 26 & \pm 11 \\
Platelet count (cmm) & 73,000 & $\pm 27,000$ \\
Dose of ASV for vasculotoxic & 250 & \pm 100 \\
$\quad$ snakebite (units) & & \\
Dose of ASV for neuroparalytic & 150 & \pm 50 \\
$\quad$ snakebite (units) & & \\
$\begin{array}{l}\text { Duration of admission for } \\
\quad \text { vasculotoxic snake bite }\end{array}$ & 10 & \pm 4 \\
$\quad$ (hours) & & \\
Duration of admission for & 6 & \pm 2 \\
$\quad$ neuroparalytic snake bite & & \\
$\quad$ (hours) & & \\
\hline
\end{tabular}

Total $13(86.66 \%)$ patients had respiratory paralysis requiring ventilatory assistance. Out of 15 patients with neuroparalytic snake-bite one $(6.66 \%)$ had developed delayed peripheral neuropathy. (Table 3 \& Figure 4)

\section{Unusual complications}

Out of 88 patients with vasculotoxic snake-bite (Russell viper) one (1.13\%) 43 year old male patient with no obvious coronary artery disease risk factors, presented with cardiac chest pain found to have acute anterior wall (STEMI) myocardial infarction. The tropinin -I was positive, which was not thrombolysed due to deranged bleeding parameters. On echocardiographic examination he had hypokinetic LV apex and anterior wall and LV apex. Coronary angiogram shows normal coronaries. (Figure 5)

Forty nine year old male patient with history of vasculotoxic envenomation (Russell viper) presented with altered sensorium found to have bilateral thalamic and right sided pontine infarction secondary to cortical venous sinus thrombosis (straight sinus thrombosis) MRI veno-gram was showing straight, sigmoid and saggital sinus thrombosis. Patient was on artificial ventilator and succumbed on 5 th day of admission due to cerebral edema, respiratory failure and trans -tentorial herniaton. (Figure 6)

Out of 15 patients with neuroparalytic (cobra) snake-bite one $(6.66 \%)$ had developed delayed peripheral neuropathy 


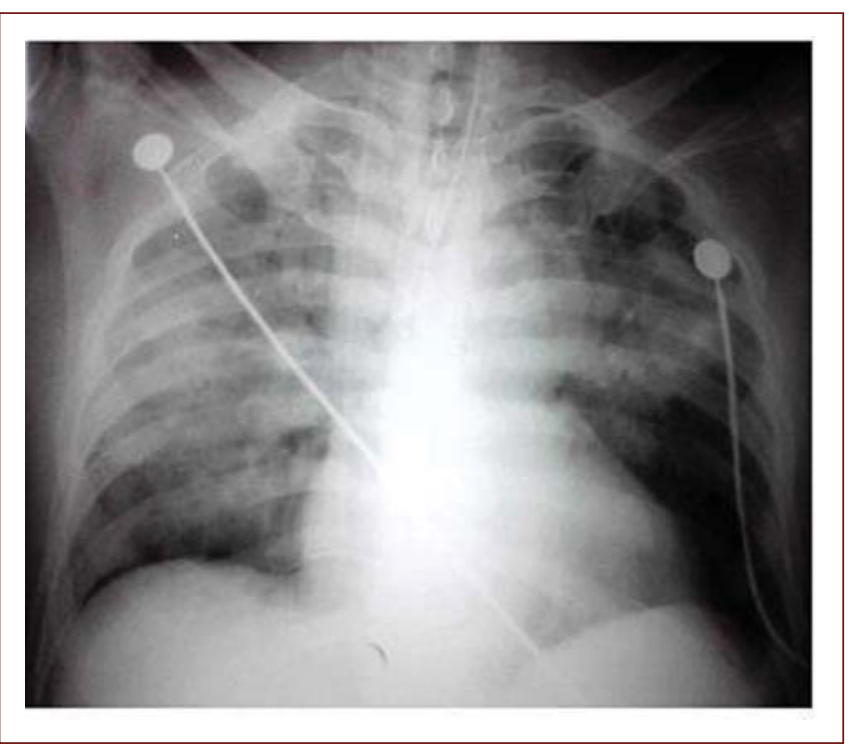

Figure 2: Acute pulmonary edema in patient with vasculotoxic snake bite with anuric renal failure

\begin{tabular}{lcc}
\multicolumn{3}{l}{ Table 3: complications of snakebite with envenomation } \\
\hline Variables & Total & Percent \\
\hline Vasculotoxic snake bite & 88 & 85.43 \\
Cellulitis ( $\mathrm{n}=88$ ) & 35 & 39.77 \\
Hypotension ( $\mathrm{n}=88)$ & 19 & 21.59 \\
Acute renal failure $(\mathrm{n}=88)$ & 12 & 13.63 \\
Neuroparalytic snake bite & 15 & 14.56 \\
Respiratory paralysis $(\mathrm{n}=15)$ & 13 & 86.66 \\
Hyperkalemia ( $\mathrm{n}=88)$ & 2 & 2.27 \\
DIC ( $\mathrm{n}=88)$ & 17 & 19.31 \\
AMI $(\mathrm{n}=88)$ & 1 & 1.13 \\
Cortical venous sinus & 1 & 1.13 \\
$\quad$ thrombosis $(\mathrm{CVT})(\mathrm{n}=88)$ & & \\
Delayed peripheral & 1 & 6.66 \\
neuropathy & & \\
Reaction to ASV & 13 & 12.62 \\
Death (n=88) & 2 & 2.27 \\
\hline
\end{tabular}

one week after snakebite. Nerve conduction velocity studies were suggestive of demylinating predominantly motor type of neuropathy, which recovered over 8 weeks with supportive line of treatment and physiotherapy.

Total $2(2.27 \%)$ patients succumbed amongst vasculotoxic snake-bite, one with severe ARF and one with CVT with ARF with cellulitis aspiration pneumonitis with septicemia. ARF was the common complication those who succumbed amongst vasculotoxic snake bite. Total $13(12.62 \%)$ patients had reaction to the ASV which was treated with desensitization with repeated small diluted dose of ASV. All 15 patients with neuroparalytic snakebite recovered and discharged with no mortality. In univariate analysis hypotension was the common presenting feature of all patients with ARF, AMI, cortical venous sinus thrombosis with odds ratio: 2.9; 'p' $<0.001$ (Table 4 \& Figure 7). The needle to ASV time was positively correlated with duration of hospital admission, complications and mortality ( +0.87 ; 'p'<0.02).

In multivariate analysis (MANCOVA) late admission $>6$ hours after envenomation was associated with ARF requiring dialysis, spreading cellulitis requiring debridement/fasciotomy amongst vasculotoxic snake-bite and need of ventilatory support amongst neuroparalytic snake-bite ('p'<0.01).

\section{DISCUSSION}

Present study highlights the burden of envenomation snakebite in western Maharashtra. Total 103 were complicated snake bite of which 88 patients were with vasculo-toxic snake bite and 15 patients were with neuroparalytic snakebite. Mainly agricultural workers 83

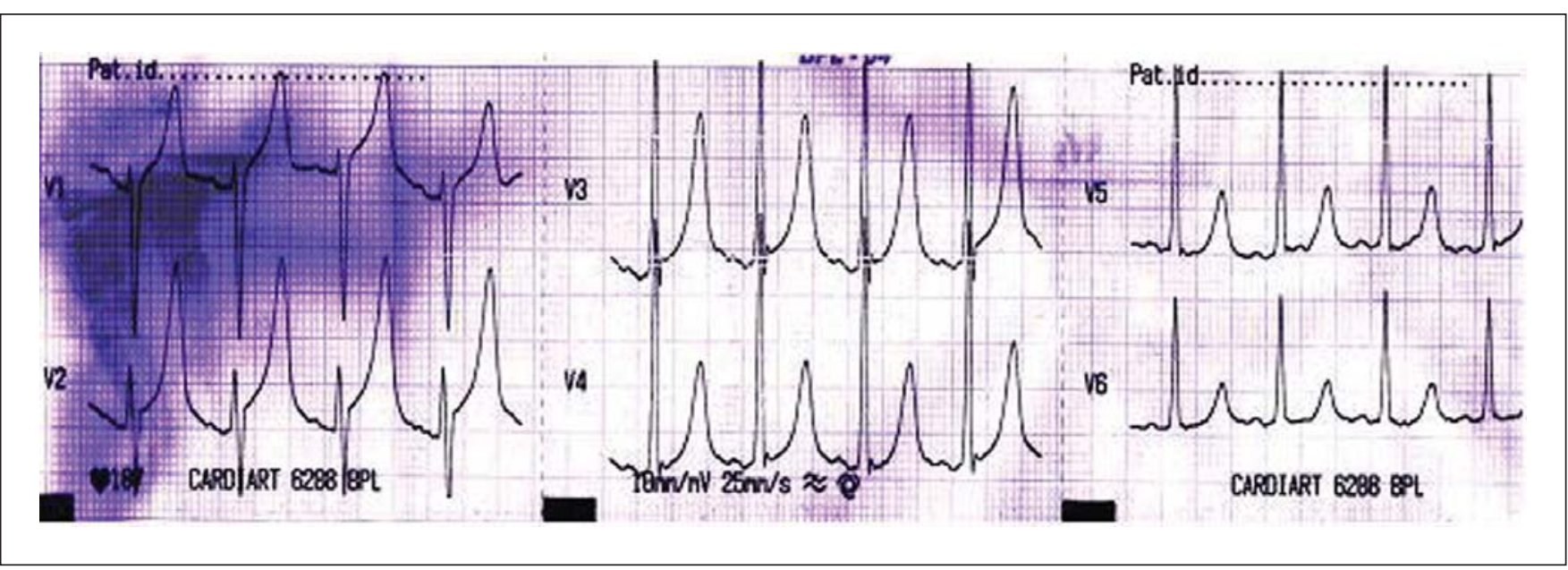

Figure 3: Tall tented 'T' waves secondary to severe hyperkalemia in patient with vasculotoxic snake bite with anuric renal failure 


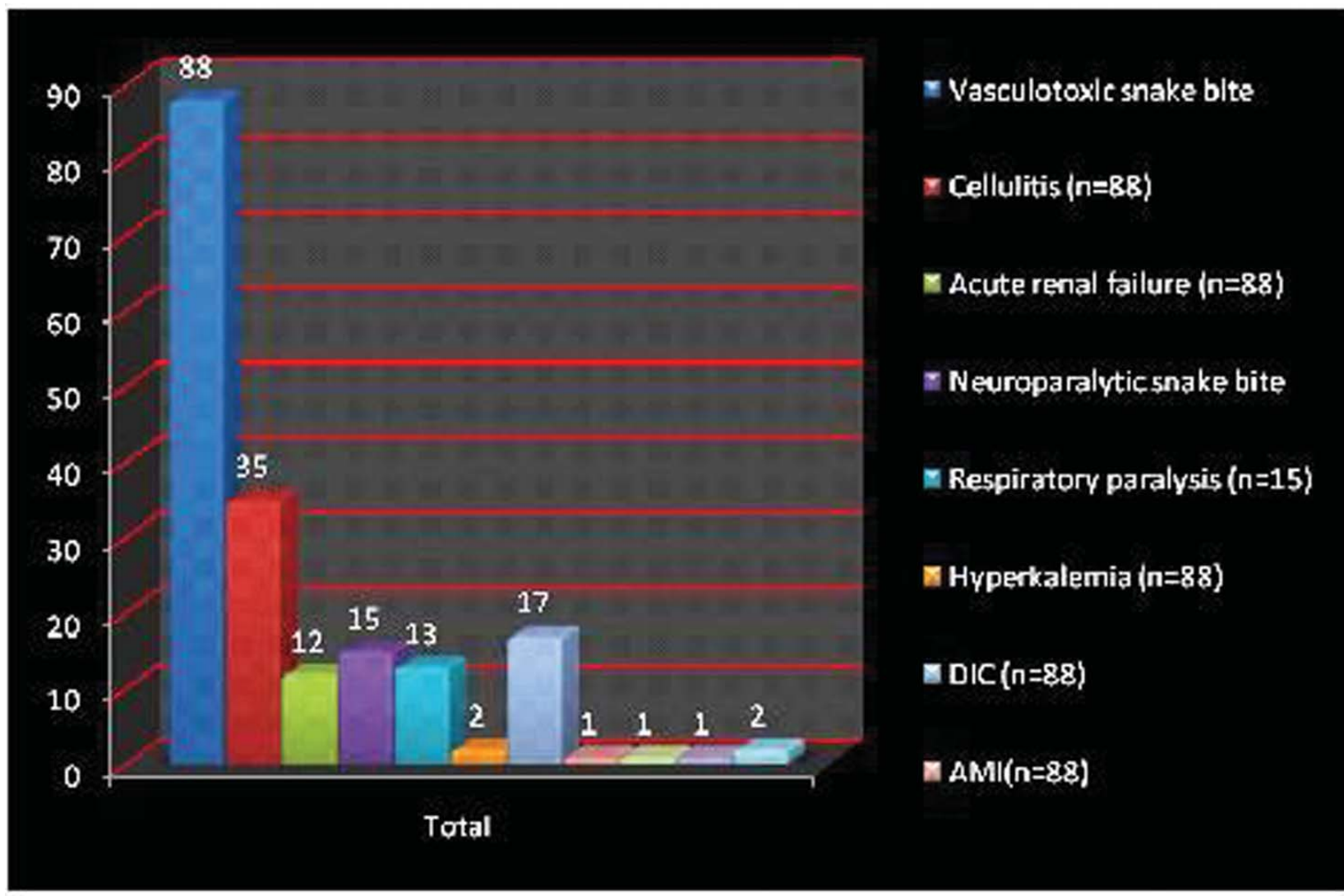

Figure 4: Coplications of envenomous snake-bite

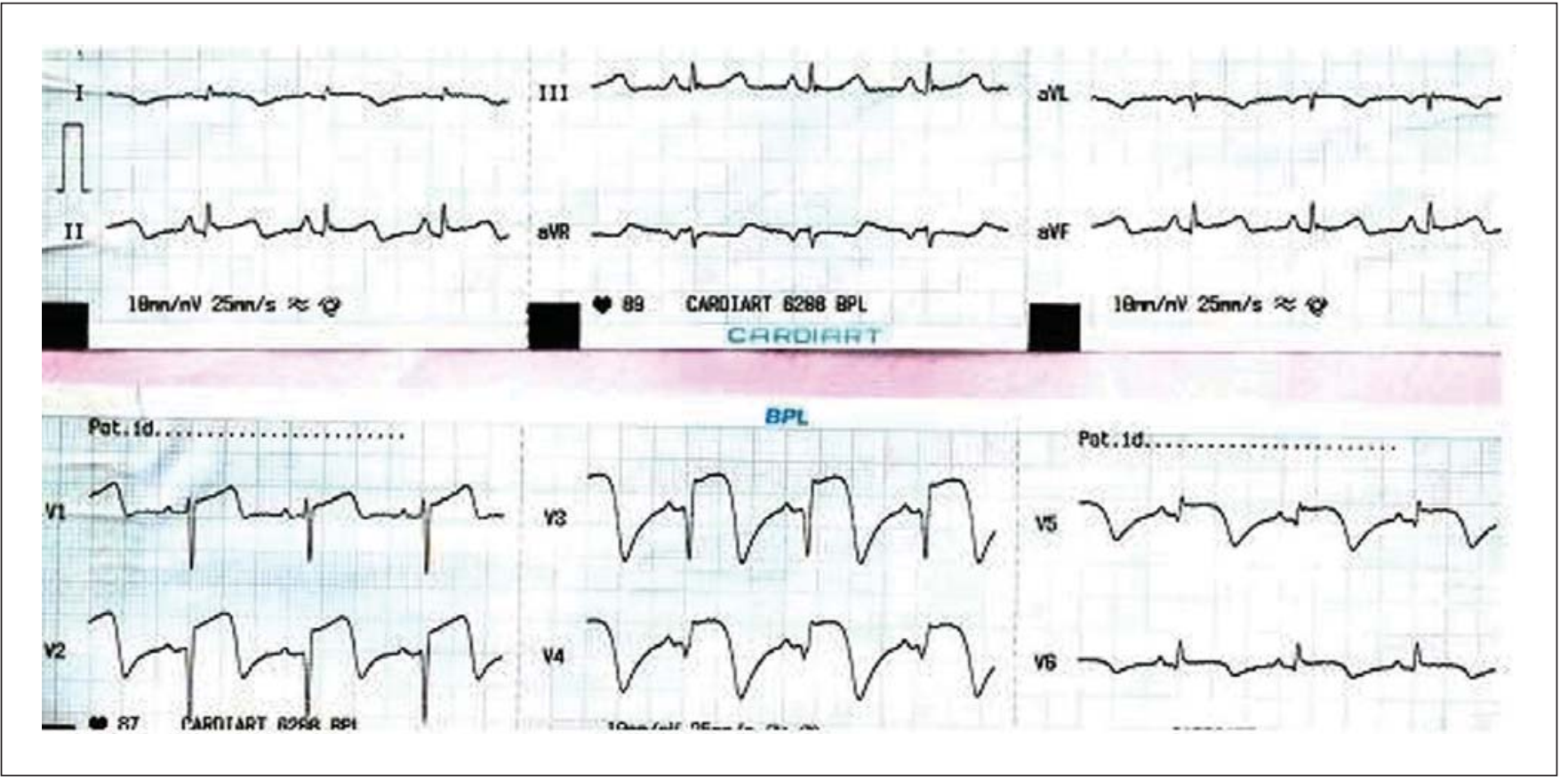

Figure 5: Acute anterior wall myocardial infarction (STEMI) with ST elevation I, aVL and V1-V6 in patient with vasculotoxic snake bite 


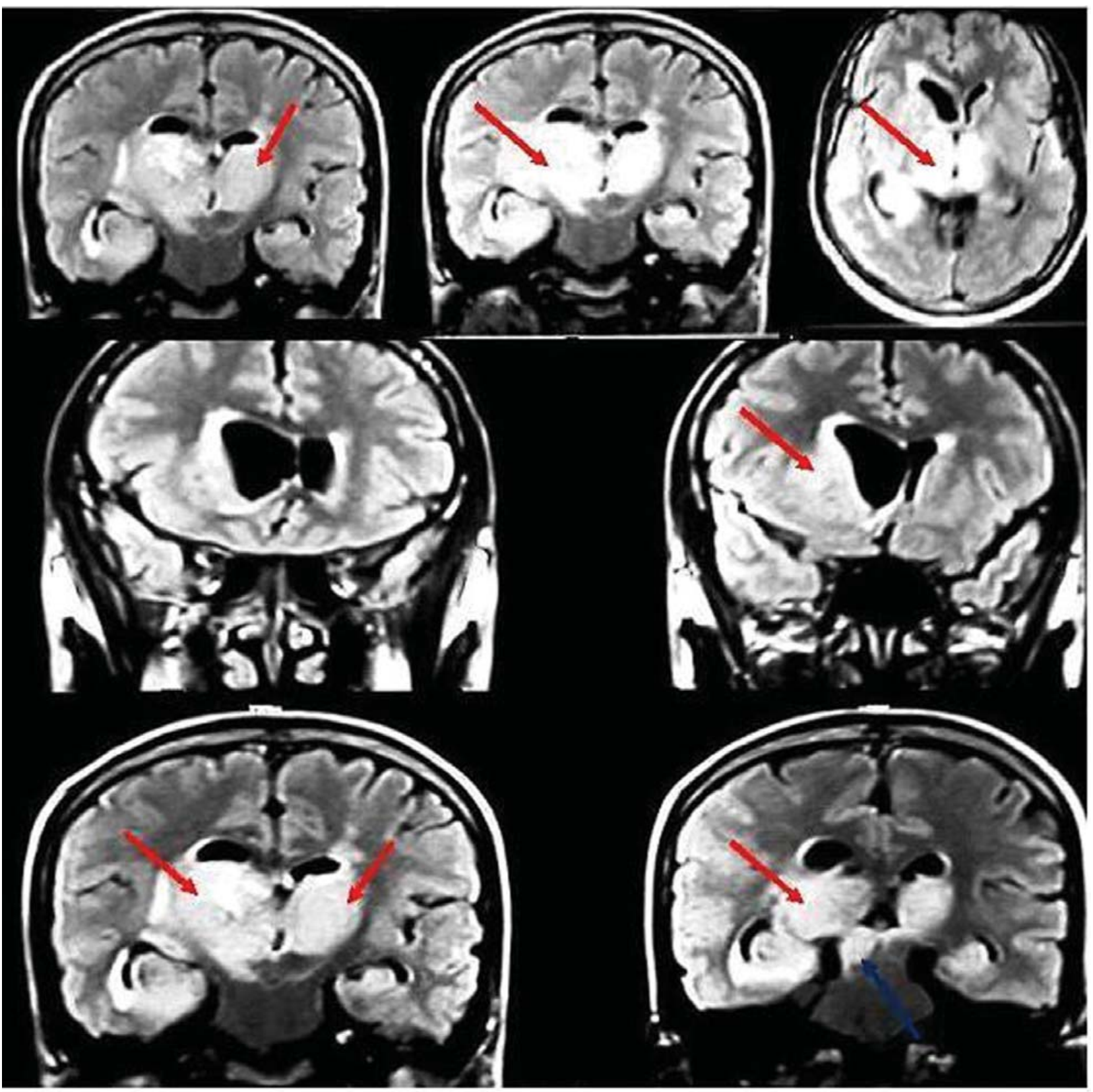

Figure 6: MRI brain shows bilateral thalamic infact secondary to straight sinus thrombosis (cortical venous sinus thrombosis)

Table 4: Relation of hypotension to the complications of vasculotoxic snake-bite

\begin{tabular}{lcc}
\hline Variables & Hypotension $(\mathbf{n = 1 9 )}$ & Percent \\
\hline DIC $(n=17)$ & 15 & 78.94 \\
ARF $(n=1)$ & 12 & 100 \\
AMI $(n=1)$ & 1 & 100 \\
Cortical venous sinus & 1 & 100 \\
$\quad$ thrombosis $(n=1)$ & & \\
Odds ratio: $2.9 ;$ ' ' $p$ ' & & \\
$<0.001$ & & \\
\hline
\end{tabular}

were affected with majority of bites in July to September month 74 . Total $35(39.77 \%)$ patients with vasculotoxic snakebite developed local cellulitis requiring fasciotomy and or debridement, 12 (13.63\%) patients developed ARF, one developed AMI and one developed cortical venous sinus thrombosis. Out of 88 patients with vasculotoxic snakebite 2 died one with severe ARF and another with CVT with ARF with cellulitis aspiration pneumonitis with septicemia. Case fatality rate for vasculotoxic snake bite 


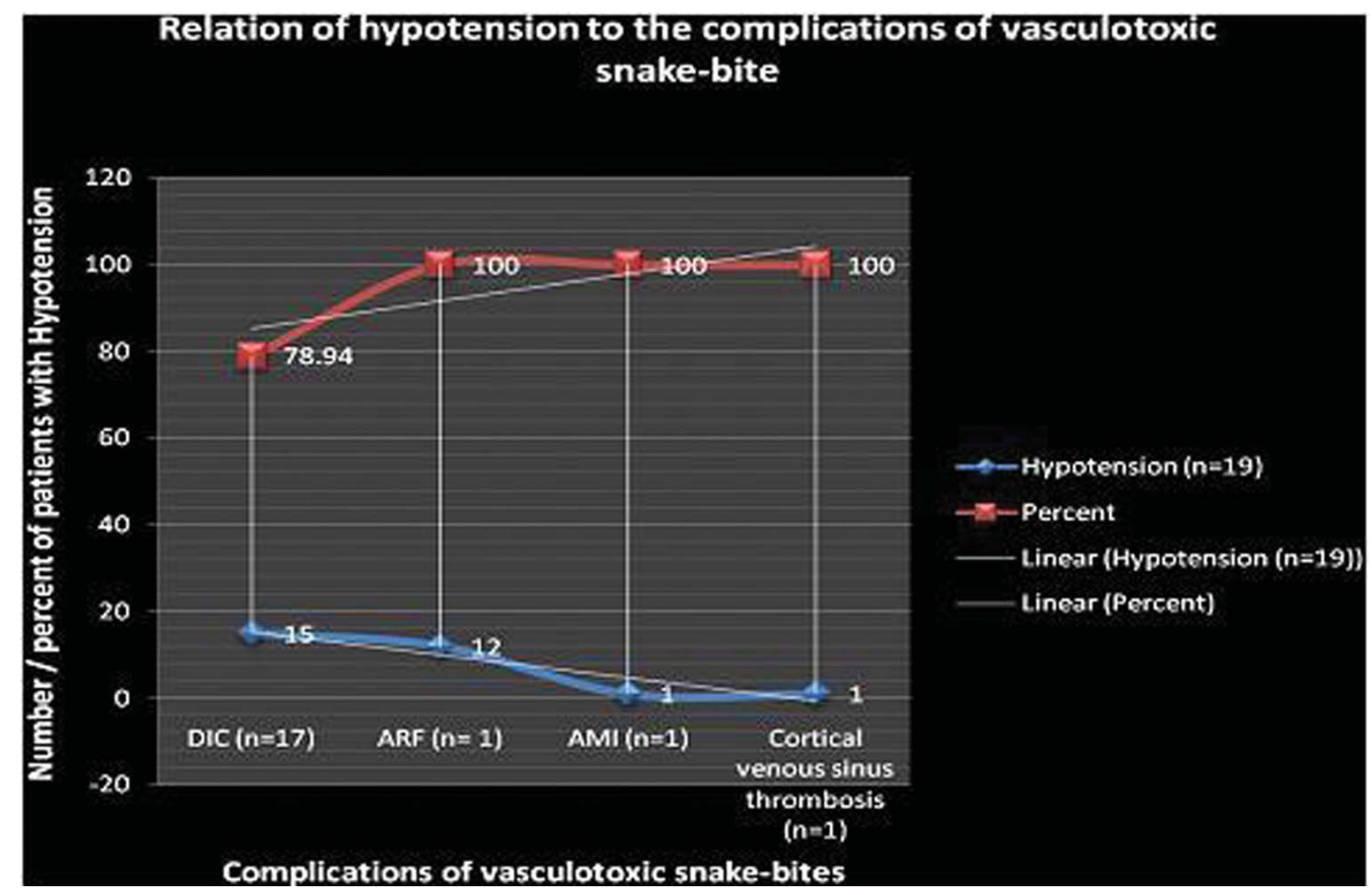

Figure 7: Correlation of hypotension and complications of envenomous snake-bite

was $2.27 \%(2 / 88)$. Out of 15 patients with neuroparalytic snake bite $13(86.66 \%)$ required artificial ventilatory support and one patient developed critical care neuropathy. Overall mortality was $1.94 \%(2 / 103)$. Hypotension was the common presenting feature of all patients with ARF, AMI, and cortical venous sinus thrombosis. We compared our results with various published studies.

Sharma $N$ et al. ${ }^{8}$ in their retrospective study of total 142 cases of snakebite there were 86 elapid bites presenting with neuroparalytic symptoms and 52 viper bites having haemostatic abnormalities. Median time to arrival at our hospital after the bite was 9 hours and mean duration of hospital stay was 8 days. Twenty seven cases had acute renal failure and $75 \%$ of all elapid bites required assisted ventilation. Seventeen of 119 patients who received antivenom had an adverse event. The average dose of antivenom was 51.2 vials for elapid bites and 31 vials for viper bites. Overall mortality rate was 3.5\%. Similarly in present study Total $12(13.68 \%)$ patients developed acute renal failure amongst 88 patients with vasculotoxic snakebite. Total $15(14.56 \%)$ patients had neuroparalytic snake bite of which $13(86.66 \%)$ patients required ventilatory assistance. Comparatively the mean for dose of ASV required for vasculotoxic snakebites was more [250 unit $( \pm 100)]$ and for neuroparalytic snakebite was less [150 units $( \pm 50)]$ in present study. Total $13(12.62 \%)$ patients have developed adverse reaction to the ASV in present study population.

Punde DP et al. ${ }^{7}$ in their 633 patients with snake-bite, 427 patients $(67.5 \%)$ had been bitten by poisonous snakes and $206(32.5 \%)$ by non-poisonous snakes. Of the 427 envenomed by poisonous snakes, $274(64.2 \%)$ were by Echis carinatus (saw-scaled viper), $71(16.6 \%)$ by cobra, $42(9.8 \%)$ by krait and $40(9.4 \%)$ by Russell viper. The requirement of anti-snake venom for treating neurotoxic envenomation was $40-320 \mathrm{ml}$ and for Echiscarinatus and Russell viper bites it was $20-250 \mathrm{ml}$. Among those envenomed by poisonous snakes, the mortality was $4.7 \%$. Similarly in our study out of 163 snake bite 103 were complicated snake bite of which 88 were vasculotoxic and 15 were neuroparalytic snake bite. Out of 88 vasculotoxic snake bite majority were Russell viper, 9w were cobra and one was krait with case fatality rate of $2.27 \%$. In present study patients with vasculotoxic snake bite required 
more ASV than neuroparalytic. The mean for dose of ASV required for vasculotoxic snakebites were 250 units $( \pm 100)$ and for neuroparalytic snakebite 150 units $( \pm 50)$.

Bawaskar HS et al. ${ }^{6}$ (2002) in their 91 cases of snakebite at Mahad of Mumbai in western Maharashtra, found that Forty-five (49.5\%) patients had snakebite without envenoming. Twenty-six $(28.6 \%)$ patients were paralyzed. Ten $(11.0 \%)$ patients died. In our study out of 163 snake bite 103 were complicated snake bite of which 88 were vasculotoxic and 15 were neuroparalytic with case fatality rate of $2.27 \%$. Compared to the mortality rate quoted Bawaskar et al, our study has less mortality. The reason for which may be late presentation in their study compared to the present study. Jayaraman $A$ et al. ${ }^{9}$ in their study of 20 cases of vasculotoxic snake bite 3 patients (15\%) died of DIC and ARF. The low mortality was seen with admission within $24 \mathrm{hrs}$. Similarly in our study $2(2.27 \%)$ patients died with vasculotoxic snake bite of which one had DIC and severe ARF and another had CVT with ARF with cellulitis aspiration pneumonitis with septicemia. Both these patients were admitted 24 hours after vasculotoxic snake bite. N Suchithra et al. ${ }^{10}$ in their study of 200 (34\%) of 586 cases with snakebites had envenoming. The species of snake was identified in $34.5 \%$ of the venomous bites. $93.5 \%$ had signs of local envenoming. The mortality rate was $3 \%$. Capillary leak syndrome, respiratory paralysis and intracerebral bleeding were the risk factors for mortality. Those who received ASV early (bite to needle time $<6 \mathrm{~h}$ ) had more severe local envenoming than those who received ASV late (bite to needle time $\geq 6 \mathrm{~h}$ ), but the latter group were more likely to suffer complications. $39.5 \%$ had complications, with acute renal failure being the most common (25.5\%). Those who received ASV late had a higher risk of developing acute renal failure. Higher rates of complications were seen in those with severe coagulopathy those who received ASV late. These findings are comparable with our study were in multivariate analysis the late admission $>6$ hours after envenomation was associated with ARF requiring dialysis, spreading cellulitis requiring debridement/fasciotomy amongst vasculotoxic snake-bite and need of ventilatory support amongst neuroparalytic snake-bite ('p'<0.01). The needle to ASV time was positively correlated with duration of hospital admission, complications and mortality $(+0.87$; 'p' < 0.02). Total $2(2.27 \%)$ patients succumbed amongst vasculotoxic snake-bite, one with severe ARF and one with CVT with ARF with cellulitis aspiration pneumonitis with septicemia. Bawaskar HS et al. ${ }^{11}$ (2008) in their 182 cases of snakebite 55 (30.2\%), 38 (20.8\%), 48 (26.3\%), 41 $(22.5 \%)$ cases were bitten by Echis carinatus (Eh), Russell's viper $(\mathrm{Rv})$, krait $(\mathrm{Kr})$ and Cobra $(\mathrm{Cr})$ respectively. In our study we had Russell viper as a common snake causing vasculotoxic snakebite and cobra as a neuroparalytic snakebite.

Hayat AS et al. ${ }^{12}$ One hundred (100) cases from both genders, from 8 to 55 years age were reviewed. There were $57(95 \%)$ viper bites (haemotoxic) having haemostatic abnormalities and $3(5 \%)$ elapid (neurotoxic) bites presented with neuroparalytic symptoms Mean time to arrival at our hospital after the bite was 3 hours and mean duration of hospital stay was 4 days. One patient had acute renal failure (ARF) and disseminated intravascular coagulation (DIC), 3\% cases of elapid bites were shifted to ICU for assisted ventilation, and 4 patients (5.5\%) had adverse effects after anti-venom administration. The average dose of anti-venom was 60 vials for viper bites and 10 vials for elapid bites. Overall mortality rate was $4 \%$. Similarly in our study the mean for dose of ASV required for vasculotoxic snakebites were 250 units $( \pm 100)$ and for neuroparalytic snakebite 150 units $( \pm 50)$. The mean duration of admission for vasculotoxic snake bite was 10 hours $( \pm 4)$ and for neuroparalytic snake bite was 6 hours $( \pm 2)$. Total $13(86.66 \%)$ patients had respiratory paralysis requiring ventilatory assistance. Total $17(19.31 \%)$ patients had clinical and laboratory parameters favoring DIC. Total $12(13.62 \%)$ patients had ARF in present study. Total 2 $(2.27 \%)$ patients succumbed amongst vasculotoxic snakebite. Total $13(12.62 \%)$ patients had adverse reaction to the ASV.

Bawaskar HS et al. ${ }^{13}$ (2004) in their study of 30 subjects of presumed snake envenoming (krait $=23$ cases, cobra $=$ 7 cases). Of 23 subjects (11 male, 12 female) bitten by kraits, 2 were deceased upon arrival, 7 died in the hospital, and 14 recovered. Of the 14 survivors, 4 required artificial respirations. Of 7 subjects ( 5 male; 2 female) encountering cobras, 2 who had been bitten were deceased upon arrival at the hospital, and 1 died suddenly of an apparent cardiac arrest. Four subjects recovered with ASV, anticholinesterase drugs, and/or artificial respiration. Similarly in present study total $15(14.56 \%)$ patients had neuroparalytic snake bite of which $13(86.66 \%)$ patients had respiratory paralysis requiring ventilatory assistance. All 15 patients with neuroparalytic snakebite recovered and discharged with no mortality. Out of 15 patients with neuroparalytic snake-bite one $(6.66 \%)$ had delayed peripheral neuropathy.

Abdallah et al. ${ }^{14}$ described a 42 year-old male, who developed an acute myocardial infarction several hours after a snakebite. The patient had no risk factors for coronary artery disease and the coronary arteries were 
normal on cardiac catheterization. Maheshwari et al. ${ }^{15}$ reported a 47 years farmer with viper snake bite, had ST segment elevation in leads II, III, aVF. Similarly in our study 43 year male patient had anterior wall ST elevation myocardial infarction with positive tropinin -I which was not thrombolysed due to deranged bleeding parameters. On echocardiographic examination he had akinetic LV apex and anterior wall and LV apex. Hypovolemic shock, coronary spasm, myocarditis and hypercoaguability are the proposed mechanism involved in acute myocardial infarction. Sanjeev et al. ${ }^{16}$ reported ischemic stroke following snake bite in an 18-year male who developed right hemiplegia with expressive aphasia following a Russell's viper bite secondary to infarct in the left middle cerebral artery territory. Similarly in present study 37 year male presented after 24 hours of snake bite (Russell viper bite) in comatose state on MRI brain found to have bilateral thalamic infarcts with pontine and mid brain involvement secondary to saggital and straight sinus thrombosis. The possible mechanisms for cerebral infarction in this scenario include disseminated intravascular coagulation, toxin induced vasculitis, dehydration and endothelial damage. Similar to our case of cortical venous sinus thrombosis $J N$ Panicker et al. ${ }^{17}$ reported cerebral infarction in a young male following viper envenomation.

Seneviratne $U$ et al. ${ }^{18}$ reported one patient developed peripheral sensory neuropathy two weeks after a krait bite. In present study cobra bite was associated with predominant motor peripheral neuropathy developed one week after envenomation and recovered near total at he end of eight weeks.

Singh $J$ et al..$^{19}$ in their study of 33 venomous snakebites in a military operational area of north India. Of 33 cases of snake bites presenting to the military hospital, 21 patients were envenomated all were neurotoxic in nature. Abdominal pain (91\%), headache (86\%), dysphagia $(86 \%)$, ptosis $(77 \%)$, diplopia $(72 \%)$, blurred vision $(72 \%)$, dyspnea $(67 \%)$, and vomiting $(62 \%)$ were the predominant clinical presentation. Polyvalent AntiSnakeVenom (ASV) [mean $180 \mathrm{ml}$; range 90-320 ml] was given to all patients with systemic manifestations, and repeated as needed. Eleven (52\%) patients received neostigmine with glycopyrrolate to counter cholinergic effects. Two patients were given ventilatory support. The average time of recovery from envenomation was 16 hours after administration of ASV. All patients recovered without sequelae. Neurotoxic snakebites predominate in our study and usually present with autonomic features along with headache, abdominal pain, ptosis, diplopia and dysphasia. Similarly in our study total 15 patients were with neuroparalytic snake-bite, all of them were successfully managed and recovered with ASV, neostigmine (anticholinesterase drugs) + atropine and ventilatory support with no mortality. Seneviratne $U$ et al. ${ }^{18}$ in their study of 56 patients with neurological manifestations of snake bite, the ptosis was the commonest neurological manifestation seen in $48(85.7 \%)$ followed by ophthalmoplegia $(75 \%)$, limb weakness $(26.8 \%)$, respiratory failure $(17.9 \%)$, palatal weakness $(10.7 \%)$, neck muscle weakness $(7.1 \%)$, and delayed sensory neuropathy $(1.8 \%)$. Sheikh et al. ${ }^{20}$ in their study of ten patients were admitted with snakebite. Male to female ratio was 1:1. Mean age of presentation was 8.9 years. Mean arrival time at hospital after bite was 3.8 hours (range 2-6 hrs). Mean dose of anti-venom given was 20.7. Mean hospitalization period was 3.6 days (range 1-5 d). Snakebite was vasculotoxic in seven and mixed (neurotoxic and vasculotoxic) in two. Levantine viper or "Gunas" (local name) was identified as a source of envenomation in five. These findings are comparable with our study. Panna Lal et al. ${ }^{21}$ in their 865 cases of snakebite with $85 \%$ of cases either got relieved or cured and $13.5 \%$ experienced mortality. Similarly in our study total 2 $(2.27 \%)$ patients succumbed amongst vasculotoxic snakebite, one with severe ARF and one with CVT with ARF with cellulitis aspiration pneumonitis with septicemia.

\section{CONCLUSIONS}

Snakebite is a common life-threatening emergency in the study area. Spreading cellulitis, DIC and ARF were the common complication with vasculotoxic snakebite. The unusual complications like acute myocardial infarction, cortical venous sinus thrombosis (CVT) and delayed peripheral neuropathy were also observed in present study. Hypotension was the common presenting feature of all patients with ARF, AMI, CVT. Russell viper was the common snake amongst vasculotoxic snake-bite and cobra was the common amongst neuroparalytic snake-bite in present study. We can conclude that delay in hospitalization is associated with poor prognosis and increased mortality rate. Early administration of ASV prevents respiratory paralysis after neuroparalytic snake bite. Patients with evidence of respiratory insufficiency after neurotoxic venom poisoning require timely intubation and artificial ventilation. Anti-cholinestrase agents may help reverse neuromuscular dysfunction caused by elapid envenoming and may accelerate recovery. Myocardial infarction is a rare complication of snakebite. The 20-min whole blood clotting test is a simple, rapid and reliable test of coagulopathy. Ready availability and appropriate use of anti-venom, ventilatory support, hemodialysis, and 
treatment of DIC and close monitoring of patients in the hospital will help to reduce mortality from snakebites. There is a pressing need to educate the public about the hazards of snakebite, early hospital referral and treatment.

\section{REFERENCES}

1. Alirol E, Sharma SK, Bawaskar HS, Kuch U, Chappuis F. Snake bite in South Asia: a review. PLoS Negl Trop Dis. 2010;26;4(1):e603.

2. David AW. Guidelines for the clinical management of snake-bites in the south-east Asia region. World Health Organization, Regional Office for South East Asia, New Delhi: 2005. p. 1-67.

3. Warrell DA. Guidelines for clinical management of snake bites in South East Asian region. SEAMEOTROPMED - Regional Centre for Tropical Medicine, WHO. 1999. Available from: http://www.searo.who.int/ LinkFiles/SDE_mgmt_snake-bite.pdf.

4. Paul V, Pratibha S, Prahlad KA, Earali J, Francis S, Lewis F. High- dose anti snakevenom versus low dose antisnakevenom in the treatment of poisonous snake bites-A critical study. J Assoc Physicians India 2004;52:14-7.

5. Warrell DA. Snake bite. Lancet. 2010 Jan 2;375(9708):77-88.

6. Bawaskar HS, Bawaskar PH. Profile of snakebite envenoming in western Maharashtra, India. Trans R Soc Trop Med Hyg 2002;4(3); 79-84.

7. Punde DP. Management of snake-bite in rural Maharashtra: a 10-year experience. Natl Med J India. 2005;18(2):71-5.

8. Sharma N, Chauhan S, Faruqi S, Bhat P, Varma S. Snake envenomation in a north Indian hospital. Emerg Med J. 2005;22(2):118-20.

9. Jayaraman A, Zawar M, Kulkarni K, Deshmukh S. Coagulation profile in patients with snake bite. Indian Journal of Hematology \& Blood Transfusion. 2001;19(3): 63-6.
10. Suchithra N, Pappachan JM, Sujathan P Snakebite envenoming in Kerala, South India: clinical profile and factors involved in adverse outcomes. Emerg Med J 2008;25:200-204.

11. Bawaskar HS, Bawaskar PH, Punde DP, Inamdar MK, Dongare RB, Bhoite RR. Profile of snakebite envenoming in rural Maharashtra, India J Assoc Physicians India. 2008;56:88-95.

12. Hayat AS, Khan AH, Shaikh TZ, Ghouri RA, Shaikh N. Study of snake bite cases at Liaquat University Hospital Hyderabad/Jamshoro. J Ayub Med Coll Abbottabad. 2008;20(3):125-7.

13. Bawaskar HS, Bawaskar PH. Envenoming by the common krait (Bungarus caeruleus) and Asian cobra (Naja naja): clinical manifestations and their management in a rural setting. Wilderness Environ Med. 2004 Winter;15(4):257-66.

14. Abdallah M. Saadeh. case report: acute myocardial infarction complicating a viper bite, Am. J. Trop. Med. Hyg., 64(5, 6), 2001, pp. 280-282.

15. Maheshwari Monika, Mittal SR, Acute Myocardial Infarction Complicating Snake Bite. JAPI 2004;52:63-64.

16. Sanjeev K. Narang Srikanth Paleti M. A Azeez Asad Tarannum Samina. Acute ischemic infarct in the middle cerebral artery territory following a Russell's viper bite. Neurology India. 2009;57(4):479-480.

17. Panicker JN, Madhusudanan S. Cerebral infarction in a young male following viper envenomation. J Assoc Physicians India 2000;48:744-45.

18. Seneviratne $U$, Dissanayake Set al.Neurological Manifestations of Snake Bite in Sri Lanka. Journal of Postgraduate Medicine. 2002;48(4), 2002:275-279.

19. Singh J, Bhoi S, Gupta V, Goel A. Clinical profile of venomous snake bites in north Indian Military Hospital. J Emerg Trauma Shock. 2008;1(2) 78-80.

20. Ahmed Sheikh Mushtaq, Qureshi Umar Amin, Rasool Akhter, Charoo Bashir Ahmed Iqbal and Qazi. Swnake bite Envenomation in Children in Kashmir. Indian Pediatr 2011;48:66-67.

21. Panna Lal, Dutta Srihari, Rotti S.B, Danabalan M, Kumar Akshay. Epidemiological Profile of Snakebite cases Admitted in JIPMER Hos pital. Indian Journal of Community Medicine. Vol. 26, No. 1 (2001-012001-03) 